\title{
O interveniente em clínica da atividade: considerações sobre seu papel e sua formação
}

\author{
Dalvane Althaus* \\ Luci Banks-Leite
}

\begin{abstract}
Resumo
Este texto visa a examinar questões referentes ao papel e modos de ação, bem como a formação do interveniente e sua inserção nesse métier. Depois de uma breve discussão sobre a relação entre intervenção e pesquisa, abordam-se alguns aspectos da démarche clínica no campo da psicologia, para apresentar, em seguida, a análise de alguns dados empíricos de uma pesquisa em andamento cujo objetivo é o estudo da formação do interveniente.

Palavras-chaves: Clínica da atividade; interveniente; formação; experiência.
\end{abstract}

\section{L’intervenant en clinique de l'activité: considérations sur son rôle et sa formation}

Résumé

Ce texte vise à examiner des questions concernant le rôle et les modes d'action, ainsi que la formation de l'intervenant et son insertion dans ce métier. Après une brève discussion sur la relation entre intervention et recherche, on aborde quelques aspects de la démarche clinique dans le domaine de la psychologie, pour présenter, par la suite, l'analyse de quelques données empiriques d'une recherche en cours dont le but est l'étude de la formation de l'intervenant.

Mots-clés: Clinique de l'activité; intervenant; formation; expérience.

O referencial teórico-metodológico da Clínica da Atividade (CA) tornou-se de fundamental importância para muitos estudos realizados em diferentes quadros institucionais no Brasil, nos últimos anos. Os trabalhos que se valem dos conceitos e da metodologia da CA objetivando a busca de respostas a questões do campo pedagógico e educacional nos interessam particularmente, considerando-se que esse é o nosso próprio terreno de ação. Nota-se que a quase totalidade dessas pesquisas empregam, entre outros, os métodos de autoconfrontação (CLOT, 1999/2006; Clot, 2008/2010) - simples e cruzada no tratamento de um amplo escopo de problemas. Sabe-se que essa metodologia exige a participação de um interveniente, cuja importância é central. Entretanto, embora surjam muitos temas ligados à atuação desse importante protagonista, diferentes escritos da área tecem considerações sobre o seu papel, mas poucas referências sobre sua formação. Movidos pelo interesse em aprofundar questões ligadas a esse "ator" - sua função, modos de agir/ intervir, suas especificidades - é de nosso interesse trazer algum subsídio que contribua para uma melhor compreensão do papel do interveniente em Clínica da Atividade e como se dá a formação ou sua constituição no interior desse quadro teórico.

\footnotetext{
*Endereço eletrônico: dalvanea@ gmail.com

***Endereço eletrônico: lbanks@uol.com.br
}

Duas questões que nos parecem pertinentes serão, brevemente, tratadas neste texto:

Qual a especificidade do interveniente nas ações por ele conduzidas? Ele é um pesquisador? É um "psicólogo" latu sensu, já que seu papel é a de um clínico da atividade? Deve ou não ser um especialista/expert no campo de atuação em que se dá a intervenção?

Como alguém se torna interveniente? Há modos/maneiras de levar os interessados a realizar trabalhos - de intervenção ou pesquisa - em CA, que possam contribuir para a constituição de interveniente? É necessário que possua alguma "qualidade" ou característica específica ou alguns pré-requisitos para se tornar um bom interveniente?

Com a finalidade de trazer elementos para a discussão desta ampla questão, apresenta-se, primeiramente, alguns pontos que têm sido alvo de debates sobre o interveniente e sua função. Em um segundo momento, discute-se a abordagem clínica em psicologia geral, e em clínica da atividade, com ênfase na figura do interveniente (CLOT, 2008/2010; CLOT e LEPLAT, 2005; OSORIO, 2016). Na terceira parte serão focalizados dados de uma pesquisa (ALTHAUS, em andamento) cujo objetivo é o estudo da formação do interveniente, em um contexto particular, qual seja, a de uma 
Universidade Federal brasileira.

\section{Em debate, o interveniente e sua função}

Com certa frequência, nos deparamos com afirmações que se referem ao interveniente, enfatizando o que ele não é, ou seja, pela negativa de sua função.

\section{- O interveniente não é um expert na área em que atua}

Em relação a esse item, a perspectiva da Clínica da Atividade é bastante clara pois traz, explicitamente, a diretriz de se afastar de estratégias clássicas de intervenção - conselhos, sugestões, instruções, que visam a "corrigir" o andamento do trabalho de um grupo em uma instituição/empresa (CLOT, 2008/2010; OSÓRIO, 2016). Assim sendo, para quem trabalha com clínica da atividade não é importante ser especialista na atividade do trabalhador, pois não irá fazer recomendações. Em outras palavras, não cabe ao interveniente avaliar, diagnosticar e/ ou emitir juízos de valor sobre o trabalho de um coletivo, nem tampouco aconselhar o emprego de um procedimento ou a implementação de mudanças na maneira de realizar tarefas. Mais adiante, voltaremos a essa questão (cf. parte 3 ).

\section{- O interveniente não é um pesquisador}

Considerando-se que o objetivo das intervenções em Clínica da Atividade se distingue daqueles que animam os empreendedores de uma investigação, um interveniente não é um pesquisador, ao menos enquanto desempenha o papel de interveniente. De fato, intervenção e pesquisa, almejam objetivos distintos: a intervenção visa a resolução de uma questão prática, a transformação nos modos de atuação de profissionais tendo em vista o desenvolvimento no/pelo trabalho dos envolvidos, enquanto $\mathrm{o}$ pesquisador busca responder questões de ordem teórico-metodológica, valendo-se de dados provenientes de situações de intervenção. Para tanto, o pesquisador "volta para a ação produzida para estudar os mecanismos de desenvolvimento ou de impedimento dessa ação" (CLOT apud OSÓRIO, 2016, p. 160) em busca de algo novo; em suma, o objetivo consiste em trazer novos elementos que contribuam para o avanço ou o remanejamento de pontos do próprio quadro da Clínica da Atividade.
Entretanto, há claras discordâncias entre os autores a respeito da (im)possibilidade de se realizar pesquisa e intervenção, simultaneamente. Lembrese que as tendências mais clássicas relativas à pesquisa, de influência nitidamente positivistas, consideram que é necessário se conhecer para transformar e para se prever o que acontecerá em situações semelhantes. Ora, a pesquisa e a intervenção filiadas à Clínica da Atividade, em clara oposição a essas ideias, se circunscrevem em outro campo, no qual o importante é "transformar para compreender" (CLOT, 2008/2010, p. 147), ou ainda, 'provocar' o desenvolvimento para ser possível estudá-lo" (CLOT, 2008/2010, p. 192). Mesmo concordando que "o transformar precede o compreender", como afirmam vários autores, existiria de fato, uma clara diferenciação das ações/funções do interveniente - a de pesquisar e a de "intervir"?

Clot (2008) defende uma distinção entre eles ou, em todo caso, a ideia de que esses dois "acontecimentos" - intervenção e pesquisa - têm lugar em momentos diferenciados. Nessa linha, Kostulski enfatiza que "a intervenção e a produção de conhecimento convocam estruturas, exigências, recursos bastante diferentes, ou mesmo, bastante incompatíveis simultaneamente" (apud OSÓRIO, 2016, p. 159). Daí decorre uma afirmação lapidar: "a pesquisa começa quando a intervenção termina" (ibidem). Ao discutir esse posicionamento, Osório discorda dessa formulação, ou seja, de que haja - ou deva existir - uma separação temporal entre pesquisa e intervenção e considera que, se pesquisa e intervenção são fonte e recurso um para o outro, seria artificial separá-las. Lembra também que pode haver intervenção sem que esta leve à realização de uma pesquisa, "mas a pesquisa não ocorre jamais sem que haja intervenção" (OSORIO, 2016, p.154).

Ainda vale notar que, apesar de adotar uma posição em que se distingue interveniente de pesquisador, frequentemente, há um certo "deslize" entre os termos interveniente/ clínico/ pesquisador nos escritos de Clot e de seus colaboradores. Alguns exemplos dessas ocorrências encontram-se, por exemplo, nas seguintes situações: ao apresentar dados de uma intervenção, o autor descreve que "os agentes de condução do TVG (...) um deles provocado por um pesquisador..." (CLOT, 2008/ 2010 , p. 139-140, grifo nosso); ao explicar a autoconfrontação simples em função da cruzada, afirma "a autoconfrontação clássica é, com efeito, orientada por um pesquisador. Ora, eis uma atividade em si na qual o trabalhador descreve e 
O interveniente em clínica da atividade: considerações sobre seu papel e sua formação

repensa sua situação de trabalho para o pesquisador e para si mesmo" (CLOT, 2008/ 2010, p. 145, grifos nossos).

Portanto, Clot e outros pesquisadores ora defendem a distinção entre pesquisador e interveniente, ora utilizam os termos como sinônimos; essa indiferenciação de termos surge igualmente em alguns estudos publicados no Brasil, recentemente (BANKS-LEITE; SMOLKA; ANJOS, 2016).

Aproveitando essa questão relativa à designação de pesquisador/interveniente/ clínico da atividade/ psicólogo e, na tentativa de desbastar um pouco o terreno no qual são realizados os estudos dessa área, discutiremos a seguir, de forma mais precisa, o entendimento que se pode ter de "clínica" e de "clínico da atividade".

\section{A perspectiva clínica}

O termo "clínica" - tanto como adjetivo, como substantivo - é de uso corrente no campo médico. No seio da Psicologia, o qualificativo "clínico" tem sido empregado com maior frequência, para designar uma área determinada - a Psicologia Clínica - e um método de trabalho, seja em pesquisa, seja na área prática ou aplicada.

Há indicações de que o "método clínico" surgiu no final do século XIX, quando Witmer, um aluno americano de Wundt, usou esse termo em seu trabalho como psicólogo ao tratar e prevenir problemas de deficiência e anomalias de desenvolvimento mental, sobretudo em crianças às voltas com dificuldades escolares. $\mathrm{O}$ método nasceu, portanto, voltado para o estudo de casos particulares, tendo em vista resolver problemas de ordem psicopatológica; entretanto, o método logo migrou para outros contextos.

Piaget empregou o método clínico em seu trabalho, adaptando-o para o estudo do pensamento da criança, ou seja, para investigar a lógica infantil. Depois de transitar pelo campo da psicopatologia, em Zurich, e também em Paris - Hospital Sainte Anne - onde entrevistara doentes mentais, passou a trabalhar com Simon, no laboratório do psicólogo Alfred Binet, na Sorbonne, que elaborara uma Escala Métrica da Inteligência. Abriu-se, então, a oportunidade de trabalhar com crianças parisienses em uma escola, tendo a incumbência de padronizar testes de inteligência. Tal tarefa não o agradou de imediato, mas Piaget a transformou e, ao invés de padronizar os testes de forma a determinar em qual idade as crianças eram capazes de responder corretamente uma e outra questão, afirmou sua intenção de "travar com meus sujeitos, conversas do tipo de interrogatórios clínicos com a finalidade de descobrir algo sobre os processos de raciocínio que se encontravam por detrás das respostas..." (PIAGET, 1966, p.135, grifo nosso). Assim, ele iniciou a elaboração do método clínico, inspirandose no já vivenciado na área psicopatológica, com o claro propósito de afastar-se do sistema de testes e provas clássicas de inteligência que se caracteriza por perguntas idênticas para todos os sujeitos, colocadas sempre nas mesmas condições, com respostas avaliadas, dicotomicamente, como corretas/erradas, e do tratamento quantitativo do conjunto de respostas, o que, por sua vez, permite um estudo estatístico da população investigada. Com a recusa de trabalhar com um questionamento fixo, Piaget desenvolveu uma abordagem singular de pesquisa junto às crianças, como se pode verificar já desde os seus primeiros livros ${ }^{1}$; esse método passou por mudanças e ajustes em função dos objetivos e temas das pesquisas, sem perder, no entanto, o caráter clínico inicial.

Para além das pesquisas de Piaget e seus discípulos, de um modo mais geral, o método clínico em Psicologia se caracteriza por alguns pontos tais como: a) aspecto casuístico, ou seja, o estudo de casos individuais que nunca são comparáveis entre si; b) análise qualitativa do que é observado; c) busca de referências a teorias ou modelos gerais; d) o uso do que pode-se denominar "intuição" (REUCHLIN, 1971). Greco, em 1968, assinalou ainda o aspecto "holístico (ou globalista), uma vez que as observações se referem a um conjunto sincrônico e diacrônico de condutas, e não apenas às únicas relações regulares entre condutas atuais e situações que as provocam" (CLOT; LEPLAT, 2005, p. 291).

No âmbito da Psicologia do Trabalho, certa elaboração e emprego do método clínico surgiu também na esteira de críticas às técnicas clássicas, de cunho predominantemente psicotécnico, como os testes de aptidões que acabam por decompor um todo em elementos distintos. A área de "Psicologia do trabalho vai especificar o método clínico dandolhe por objeto o estudo da situação de trabalho, isto é, da dupla formada de um lado pelo sujeito, de outro, pela tarefa e seu meio ambiente" (CLOT; LEPLAT, 2005, p. 292). Há pesquisas mais voltadas para o exame da tarefa a ser realizada, como as descritas por Lahy e Pacaud, e outras mais 
dedicadas ao outro polo - estudo dos trabalhadores enquanto realizam suas tarefas. Em todo caso, há meio século, Faverge, bem conhecido por seus trabalhos em Ergonomia, criticava a teoria das aptidões e ressaltava a importância de uma abordagem clínica em sua área: "minha experiência me convenceu da necessidade de dar um lugar essencial à démarche clínica em psicologia industrial" (CLOT; LEPLAT, 2005, p. 295).

Entre as várias questões levantadas a propósito dessa abordagem, uma delas diz respeito à produção de conhecimento. Afinal, se tal démarche focaliza o estudo de casos, de situações singulares, como o conhecimento aí gerado pode ser transposto para outras situações? Em outras palavras, como ascender à generalização, essencial para incrementar a teoria? Este problema nos leva também a outro, qual seja, a relação entre método clínico e o método experimental; seriam opostos, incompatíveis ou pode-se também aceitar a existência de um método clínico experimental ou de uma articulação entre eles? Piaget já afirmava que "o exame clínico participa da experiência pois o clínico se coloca problemas, levanta hipóteses, faz variar as situações (...) em função das variações provocadas pela conversa" (CLOT; LEPLAT, 2005, p. 300).

Mas como essa relação se apresenta no campo da Clínica da Atividade? Afinal, nessa ótica, o termo Clínico é um substantivo, e dá-se ênfase à ação e não à produção de conhecimento. Considerando-se, pois, a primazia da ação, a Clínica da Atividade busca promover o desenvolvimento da atividade pela transformação dos atores envolvidos para depois compreender, como já afirmado na primeira parte.

Resumidamente, a intervenção se dá no quadro de um dispositivo no qual ocorrem diálogos entre os profissionais - um coletivo de trabalho para que aí se desenvolva "uma atividade nova sobre suas atividades anteriores que afete a situação de trabalho deles e que tenha a ver com seu métier" (CLOT, 2008, p. 67), entendendo-se que o métier não é apenas o gesto profissional situado, mas também o gênero profissional ${ }^{2}$. O objetivo fundamental da intervenção é o de tornar possível o desenvolvimento do poder de agir dos profissionais sobre seu próprio métier, levando-se em conta as quatro dimensões deste: impessoal, transpessoal, interpessoal e o pessoal.

Mas, afinal, aprende-se a ser interveniente?
Ao comentar que o interveniente não é um pesquisador - em todo caso enquanto realiza a intervenção - Clot não descarta a importância dos conhecimentos, bem ao contrário.

O psicólogo do trabalho que faz Clínica da Atividade enfrenta situações difíceis. Ele deve trabalhar com instrumentos, entre os quais os conceitos são tão importantes quanto o coletivo de trabalho, no qual ele pode colocar em discussão suas 'maneiras de fazer'. Isso supõe experiência, "métier" (CLOT, 2008, p 68).

Essa afirmação encerra algumas indicações importantes a respeito do trabalho do interveniente.

Explicita-se que os conceitos são de importância fundamental e devem fazer parte do leque de conhecimentos daquele que trabalha em CA, pouco importa se este é denominado de interveniente, de pesquisador ou de psicólogo do trabalho. Esses conceitos, inclusive os de natureza metodológica, constituem o quadro teóricometodológico elaborado ao longo de anos, tais como expostos em inúmeros artigos e livros (CLOT, 1999/ 2006; 2008/2010). Por sua vez, tais conceitos pressupõem igualmente um conhecimento básico de autores ligados à perspectiva históricocultural em Psicologia, sobretudo Vygotski e Bakhtin, sobre os quais se assentam muitos elementos da CA.

Entretanto, o conhecimento de um arcabouço teórico não é suficiente, daí a importância do coletivo de trabalho do qual participa o interveniente, já que é no seio desse grupo que se discutem modos, maneiras de se realizar a intervenção propriamente dita. Tal fato se relaciona à necessidade de experiência - um dos traços marcantes daquele que se engaja em uma démarche clínica - e nos permite refletir sobre como se dá a transmissão desses modos de ação; nesse sentido, os mais experientes desempenham um papel preponderante e seriam, por assim dizer, os mentores, tutores dos menos experientes ${ }^{3}$.

Ao se lançar na intervenção, como o que é conhecido em teoria articula-se com as ações do interveniente? Essa é uma questão delicada, uma vez que Clot enfatiza a necessidade do interveniente lutar contra o que ele já sabe. "Libertar-se dessa tentação é um desafio para o métier de interveniente". (...). A conquista da "ignorância" é a condição de possibilidade da ação no ponto de partida, como projeto e como engajamento" (CLOT, 2008, p.77). Ou seja, é condição para 
O interveniente em clínica da atividade: considerações sobre seu papel e sua formação

observar, acolher ou mesmo "provocar", de maneira hábil, as transformações, o surgimento do novo, do inesperado.

Essa questão vai muito além do que se passa no âmbito da CA, pois é um problema para os que se propõem a trabalhar com uma orientação/ démarche clínica. Por isso, trabalhar como clínico se aproxima de uma arte, com improvisos essenciais de todo o trabalho artístico, sem esquecer que para improvisar, é necessário ter muitos conhecimentos, além de habilidade e destreza. Trata-se de uma arte, pois deve-se lidar cada vez com situações que se desenvolvem sempre de maneira singular, única e também porque exige modos de ação que devem ser (re)criados a todo instante. A intuição, apontada como uma característica do método clínico (cf. primeira parte), desempenha também um papel importante, mesmo sabendo-se que esta não é um dom ou uma competência rara, mas assenta-se em conhecimentos e em experiências no quadro do próprio métier. Apesar das dificuldades, a démarche clínica "não está condenada a permanecer uma arte intransmissível” (CLOT; LEPLAT, 2005, p. 312).

\section{A formação de uma interveniente}

\section{Questões preliminares}

Antes de tudo, cabe precisar o quadro no qual este trabalho se realiza ${ }^{4}$ O local é uma instituição centenária, originária das Escolas de Aprendizes Artífices, em 1909 (LEITE, 2010). Desde seu surgimento até os dias atuais, passou por várias transformações, tendo por finalidade, durante muitos anos/décadas, a formação de técnicos, primeiramente no ensino médio e mais tarde, a partir de 1978, em nível universitário. No momento, oferece cursos em diferentes áreas, inclusive as de Letras e Ciências Humanas, tanto no nível da Graduação como em programas de Pós-graduação. Os docentes que trabalham nessa instituição são formados em suas áreas, e possuem, em grande maioria, o título de doutor.

$\mathrm{Na}$ Lei de Diretrizes e Bases para a Educação Nacional (LDBEN) 9394/96, artigo 66, afirma-se que "a preparação para o exercício do magistério superior far-se-á em nível de pósgraduação, prioritariamente em programas de mestrado e doutorado"; constata-se, porém, que os docentes ingressam nas Instituições de Ensino Superior preparados academicamente para transmitir conhecimentos específicos de suas áreas de pesquisa mas, frequentemente, pouco preparados para exercer as atividades de ensino (LEITE; BERNARDO; MOREIRA, 2017; PIMENTA; ANASTASIOU, 2002/2010).

Nesta instituição não é diferente, embora note-se uma preocupação com o acompanhamento pedagógico de seu corpo docente, uma vez que foi criado, em 2009, um Departamento de Educação (DEPED), e vinculado a ele, um Núcleo de Ensino (NUENS). Ambos têm a finalidade de implementar ações de formação docente continuada voltadas aos professores da instituição. O DEPED não é, portanto, um Departamento Acadêmico que oferece Cursos de Graduação, como normalmente ocorre nos Institutos ou Faculdades de Educação em Universidades, mas sim um Departamento TécnicoAdministrativo com a finalidade de apoiar o desenvolvimento de práticas docentes (ALTHAUS, 2013).

No início, as atividades realizadas pelo DEPED /NUENS visavam a apoiar a Instituição na organização de semanas de planejamento com cursos e palestras, dirigidas aos docentes, e proferidas por especialistas da área da educação, externos à instituição. Contudo, essa abordagem, semelhante ao que faz um expert, uma vez que esses especialistas eram apresentados como conhecedores dos problemas e dificuldades dos professores, e por isso mesmo, trazendo respostas/ sugestões prontas, era amplamente rejeitada pelos docentes que alegavam não encontrar uma relação entre o que os especialistas lhes recomendavam e o que, de fato, acontecia em suas salas de aula (ALTHAUS, 2013).

Nesse contexto, ingressou na instituição um professor-pesquisador com formação na área da Clínica da Atividade, que passou a integrar o DEPED/ NUENS. A partir de então, organizou-se um grupo de pesquisa, interessado em estudar esse quadro teórico-metodológico, uma vez que se descortinava aí, a possibilidade de novas formas de trabalho junto à coletividade de professores (ALTHAUS, 2013). De fato, logo notou-se a grande diferença entre essa abordagem e a anterior, bem como as possibilidades abertas para trabalhar com professores, diante dos problemas por eles enfrentados em sala de aula. Porém, dada a complexidade da Clínica da Atividade, logo constatou-se a necessidade de formar intervenientes para atuarem junto ao coletivo de professores, atendendo às suas demandas e necessidades. Como, então, proceder para formá-los?

Dois aspectos, tais como indicados por Clot 
(2008), orientaram a escolha de atividades implementadas pelo grupo de pesquisa Linguagem, Atividade e Desenvolvimento Humano:

$\mathrm{O}$ primeiro aspecto leva em consideração que "o psicólogo do trabalho que faz CA (...) deve trabalhar com instrumentos, entre os quais os conceitos" (cf. parte 2). No quadro do grupo de pesquisa, composto por professores-pesquisadores, pós-graduandos e alunos da área de Letras, de Pedagogia e de Psicologia, que têm algum conhecimento da perspectiva histórico-cultural, procura-se aprofundar e discutir conceitos de autores como Bakhtin (BAKHTIN, 1979/2011) e Vigotski (1984/2007), bem como os relativos à Clínica da Atividade.

$\mathrm{O}$ segundo aspecto diz respeito à experiência. Ora, como proceder para implementar as experiências de intervenientes em formação? Primeiramente, através da observação de outros intervenientes, seja através de vídeos, seja por observação direta de outros mais experientes que atuam na área; em seguida, participando ativamente das autoconfrontações. No início, essa experiência se realiza sempre em pares de intervenientes, de forma tal que o interveniente em formação realiza autoconfrontações com um interlocutor dessa área.

Foi a noção de ZDP - Zona de Desenvolvimento Proximal, de Vigotski (1984/2007), que nos inspirou a realizar essa experiência a dois. Acredita-se que as atividades que um interveniente em formação não consegue ainda realizar sozinho, poderá efetuar com o auxílio de outra pessoa mais competente, e no futuro será capaz de ter autonomia nessa tarefa. Vigotski (1984/2007) assevera que tal processo não é nem linear, nem automático, mas é entendido como um processo de aprendizagem em que o menos experiente interage com outro mais experiente em determinado contexto, e pode desenvolver, assim, modos de realizar determinadas ações ou tarefas.

Mais especificamente, ao se referir aos processos de desenvolvimento e aprendizagem na criança, Vigotski afirma que

O aprendizado desperta vários processos internos de desenvolvimento, que são capazes de operar somente quando a criança interage com pessoas em seu ambiente e quando em cooperação com seus companheiros. Uma vez internalizados, esses processos tornam-se parte das aquisições do desenvolvimento independente (VIGOTSKI, 1984/2007, 103).

Algo dessa ordem se passa também com os adultos.

No estudo em questão, no momento da constituição do grupo, o professor-pesquisador, já experiente nos procedimentos metodológicos da Clínica da Atividade, realizou autoconfrontações em conjunto com a pedagoga-pesquisadora da instituição, em processo de formação como interveniente. Em seguida, a pedagoga-pesquisadora passou a colaborar na formação de outra interveniente, desempenhando o papel de interveniente principal (IP) nas autoconfrontações realizadas por essa dupla. Compreende-se que, em uma perspectiva clínica, o estudo teórico, embora seja essencial, precisa ser complementado com a experiência prática, iniciando-se com a supervisão de outro.

\section{Primeiras experiências}

Neste caso, há uma dupla constituída pela IP e por uma auxiliar (IA), que está iniciando sua experiência como interveniente. Não se trata, contudo, de uma rígida hierarquia de papéis, mas sim do estabelecimento de uma interlocução em que ambos intervêm. No decorrer das autoconfrontações, a função de IP é a de conduzir as autoconfrontações e, ao mesmo tempo, servir de suporte para a formação de IA, enquanto esta observa a atuação de IP junto aos professores, podendo intervir quando se apresentam situações em que ela se sente apta a atuar.

As etapas do trabalho, envolvendo os professores de disciplinas ministradas em diferentes cursos dessa instituição, seguiram as instruções gerais das pesquisas em CA (cf. CLOT, 2008/2010, p. 144; 238-241), e foram, assim, realizadas:

$\mathrm{Na} 1^{\mathrm{a}}$ fase, que antecede às autoconfrontações, as intervenientes constituíram duplas de professores voluntários em reunião em cada departamento acadêmico da instituição, na qual foi proposto este trabalho de $\mathrm{CA}$ como alternativa para buscar soluções aos problemas de ensinoaprendizagem que surgem no dia a dia desse meio (cf apontado no item questões preliminares); observaram os professores em sala de aula e iniciaram os diálogos com estes; filmaram uma aula de cada professor e selecionaram uma sequência de imagens em atividade, de cada professor, que se tornaram objeto de análise nas fases seguintes. $\mathrm{Na}$ $2^{\mathrm{a}}$ fase, as intervenientes conduziram autoconfrontações com os professores - uma sessão simples (ACS) com cada um, e uma sessão cruzada (ACC), igualmente, com cada professor - a partir de 
O interveniente em clínica da atividade: considerações sobre seu papel e sua formação

recorte de material audiovisual. Na $3^{\mathrm{a}}$ fase, após as autoconfrontações, as intervenientes, juntamente com as duplas de professores, retornaram aos departamentos acadêmicos, aos quais os professores se vinculam, para lhes apresentar os resultados dos diálogos; a partir dessa discussão coletiva é que são pensados e planejados encaminhamentos acerca das questões abordadas nas autoconfrontações.

A interveniente em formação participou das três fases. Porém, para este estudo, optou-se por analisar os dados de três momentos da segunda fase, em que ela participa na condução das autoconfrontações.

\section{Primeiro momento}

Serão apresentados, neste artigo, três momentos de autoconfrontações simples, envolvendo professores de Ciências Contábeis e de Matemática ${ }^{5}$.

O primeiro momento, ocorreu em uma ACS, com um professor do Departamento de Ciências Contábeis, o Professor Boaventura (PB). $\mathrm{Na}$ sequência de imagens utilizadas para dialogar sobre o que ocorreu na aula, o PB aparece realizando as seguintes ações: inicialmente, resolve algumas questões pertinentes ao planejamento e replanejamento da aula em conjunto com os alunos; na sequência passa para a correção de um exercício, passa-a-passo, no quadro.

Nessa sequência da ACS, abaixo, o PB se põe a explicar as diferentes formas de correções de exercícios, dentre elas as correções de provas, que ele faz de forma individual em planilhas do Excel para agilizar o retorno aos alunos.

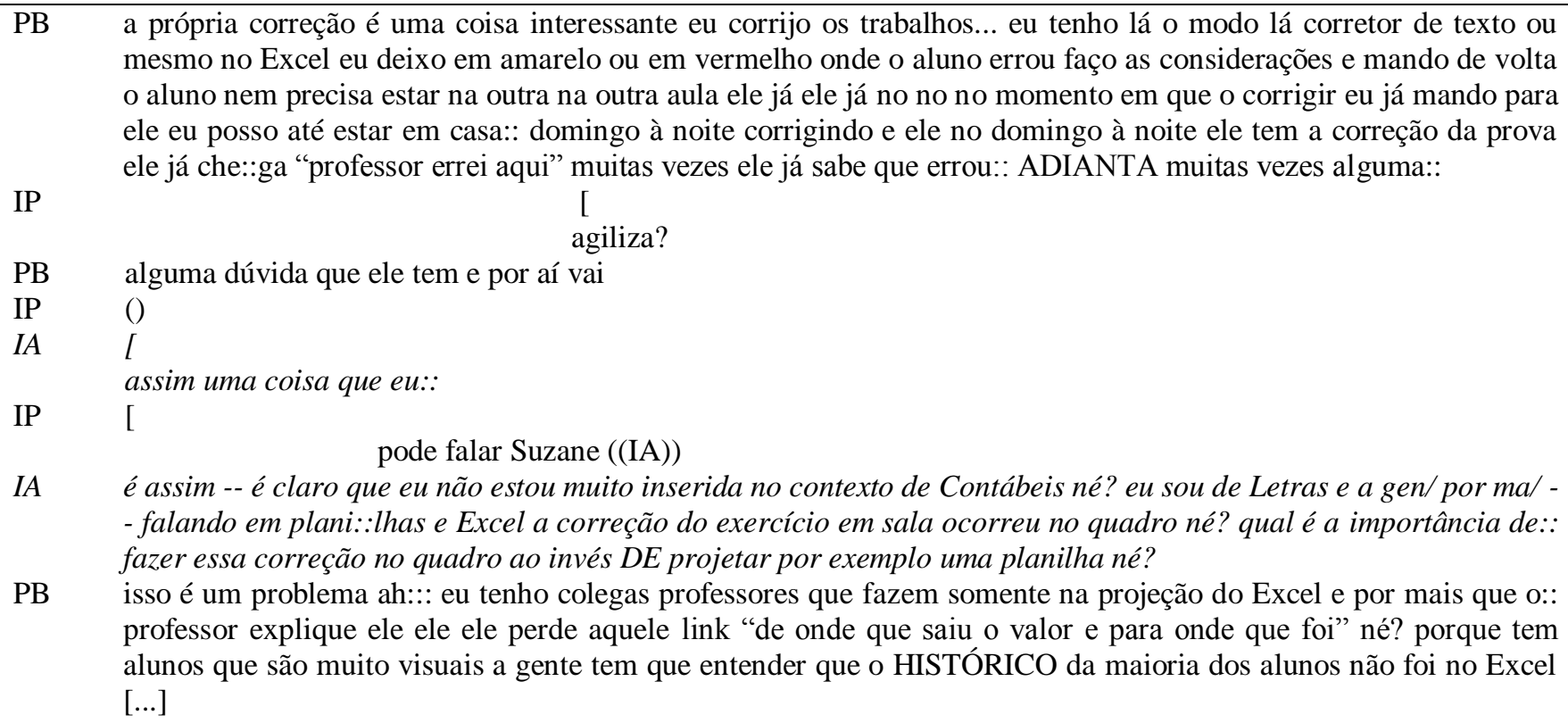
mesmo no Excel eu deixo em amarelo ou em vermelho onde o aluno errou faço as considerações e mando de volta o aluno nem precisa estar na outra na outra aula ele já ele já no no no momento em que o corrigir eu já mando para ele eu posso até estar em casa:: domingo à noite corrigindo e ele no domingo à noite ele tem a correção da prova ele já che::ga "professor errei aqui" muitas vezes ele já sabe que errou:: ADIANTA muitas vezes alguma::

IP

PB alguma dúvida que ele tem e por aí vai agiliza?

IP ()

IA $\quad[$

assim uma coisa que eu::

IP $\quad[$

pode falar Suzane ((IA))

IA é assim -- é claro que eu não estou muito inserida no contexto de Contábeis né? eu sou de Letras e a gen/ por mal - falando em plani::lhas e Excel a correção do exercício em sala ocorreu no quadro né? qual é a importância de:: fazer essa correção no quadro ao invés DE projetar por exemplo uma planilha né?

PB isso é um problema ah::: eu tenho colegas professores que fazem somente na projeção do Excel e por mais que o:: professor explique ele ele ele perde aquele link "de onde que saiu o valor e para onde que foi" né? porque tem alunos que são muito visuais a gente tem que entender que o HISTÓRICO da maioria dos alunos não foi no Excel $[\ldots]$

Após o professor explicar seu procedimento de correções de exercício de provas, nota-se que a IP tenta se pronunciar e sua fala fica inaudível, "( )", porque IA a interrompe para anunciar que deseja fazer uma pergunta: “assim uma coisa que eu::". Ao se alongar no "eu::", IA demonstra certa insegurança. Então, a IP incentiva que IA fale: "pode falar Suzane". Diante disso, a interveniente em formação, IA, inicia justificando seu pouco entendimento na área de Contábeis: "é assim -- é claro que eu não estou muito inserida no contexto de Contábeis né? eu sou de Letras e a gen/ por mal --". Dessa forma, ela busca uma maneira indireta para entrar na questão seguinte: "falando em plani::lhas e Excel a correção do exercício em sala ocorreu no quadro né? qual é a importância de:: fazer essa correção no quadro ao invés DE projetar por exemplo uma planilha né?". Essa pergunta de IA leva o professor a explicitar seu modo de agir e a diferença entre demonstrar o resultado em uma planilha e colocar o processo detalhadamente no quadro para que aluno possa ver de onde o valor vem e para onde se destina. Segundo PB, trata-se de um problema para o coletivo de trabalho em Ciências Contábeis. 


\section{Segundo momento}

O segundo momento ocorreu em uma ACS, com outro professor de Ciências Contábeis, o Professor Cândido (PC). Na sequência de imagens do professor em sala de aula, utilizadas para tema da autoconfrontação, PC esteve desenvolvendo as seguintes ações: primeiro, tenta ligar o multimídia, para o utilizar como instrumento de aula, sem sucesso; a seguir, parte para a leitura de um livro, alternando tal leitura com explicações orais e escritas no quadro.

O excerto da ACS que trazemos, ocorre na sequência em que PC estava explicitando a dificuldade em manter a atenção dos alunos por cinco aulas seguidas; a interveniente em formação questiona o professor a respeito desse problema e a interveniente principal aproveita para explorar um pouco mais a pergunta feita pela IA.

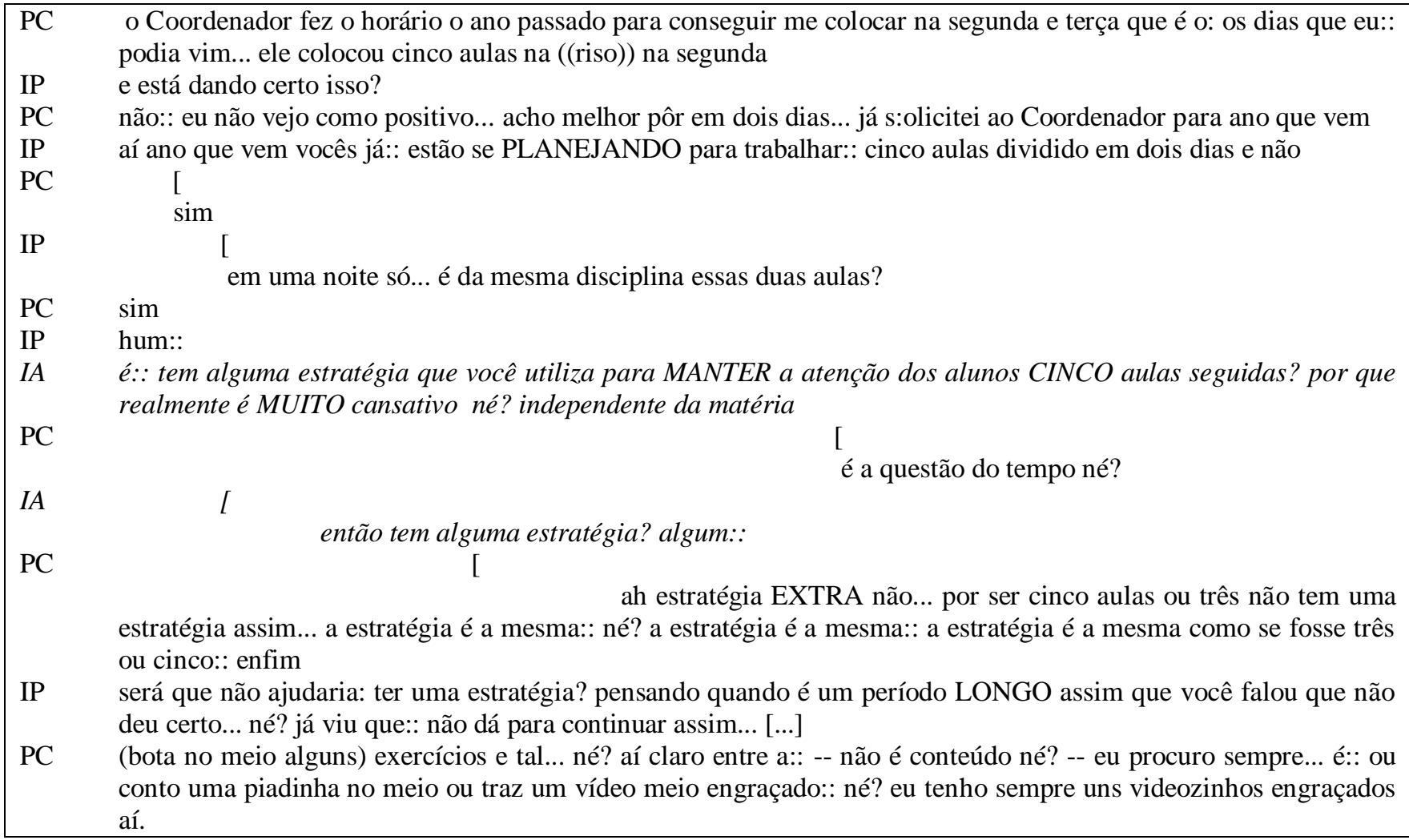

Esse trecho inicia-se com PC afirmando que, na disciplina em que a aula foi filmada, há cinco aulas seguidas no turno da noite (das $18 \mathrm{~h} 40 \mathrm{~min}$ às $23 \mathrm{~h}$, com um intervalo de dez minutos) e manifesta um riso um pouco nervoso. Esse riso parece indicar que há um problema com tal horário. IP pergunta se está dando certo e PC responde que não e que já solicitou ao Coordenador do Curso, uma alteração para o ano seguinte. Diante dessa dificuldade do professor a IA lança uma questão, iniciando seu enunciado pela alternância com IP: "é:: tem alguma estratégia que você utiliza para MANTER a atenção dos alunos CINCO aulas seguidas? por que realmente é MUITO cansativo né? independente da matéria". Essa pergunta sugere que é necessário ter formas de trabalhar para escapar de uma situação que corre o risco de se tornar monótona. A questão colocada por IA é uma tentativa de explorar com PC o real da atividade, as possibilidades não realizadas, a partir da atividade realizada em condições adversas - cinco aulas seguidas. IA mostra-se segura, sem justificar-se antes de perguntar, e, além disso, as entonações são mais fortes: "MANTER", "CINCO" e "MUITO". A pergunta parece afetar PC, pois ele interrompe IA e lhe diz: "é a questão do tempo né?" PC explicita o que estava subentendido à pergunta, e IA, por sua vez, interrompe, o professor para lhe repetir a questão de forma bem objetiva: "então tem alguma estratégia? algum::". Novamente PC interrompe IA, e responde: "ah estratégia EXTRA não... por ser cinco aulas ou três não tem uma estratégia assim... a estratégia é a mesma:: né? a estratégia é a mesma:: a estratégia é a mesma como se fosse três 
O interveniente em clínica da atividade: considerações sobre seu papel e sua formação

ou cinco:: enfim". PC se vê diante de algo que lhe parece difícil explicar, pois repetiu a palavra "estratégia" por cinco vezes a fim de reafirmar que não tem formas diferentes para trabalhar. Então, IP insiste no tema introduzido pela questão de IA: "será que não ajudaria: ter uma estratégia? pensando quando é um periodo LONGO [...]". IP não só retomou a questão introduzida por IA, como também assumiu a posição valorativa e sugestiva de que ter uma estratégia extra, seria algo positivo. Vale notar que essa intervenção é pautada na fala do professor "eu não vejo como positivo..." (ter cinco aulas seguidas), o que levou a IP a retomar: "você falou que não deu certo... né? já viu que:: não dá para continuar assim...". Nesse caso, IA também exerce influência sobre IP, já que esta passou de uma forma mais neutra para uma forma menos imparcial. Pergunta à qual PC responde: "(bota no meio alguns) exercícios e tal... né? aí claro entre a:: -- não é conteúdo né? -- eu procuro sempre... é:: ou conto uma piadinha no meio ou traz um vídeo meio engraçado:: né? eu tenho sempre uns vídeozinhos engraçados aí". Embora o PC tenha dito, inicialmente, que "não tem uma estratégia", diante da retomada da questão pela IP, ele lembra que procura ter momentos de descontração com "piadinhas" e "vídeozinho engraçados", no diminutivo e, além disso, frisa que "não é conteúdo". Em relação à atividade docente, estaria PC fugindo do gênero profissional, uma vez que, os "vídeozinhos" e as "piadinhas" não teriam relação com o conteúdo? Ou estaria estilizando diante da dificuldade para manter a atenção dos alunos por cinco aulas seguidas? Seria esta uma estratégia já utilizada por diversos docentes em contextos diferentes? Trata-se de perguntas que deixamos em aberto, sem elementos para uma interpretação mais apurada.

\section{Terceiro momento}

O terceiro momento ocorreu em outra ACS, com um professor de Matemática, o Professor Dermeval (PD). Na sequência de imagens do professor em sala de aula, utilizadas para tema da autoconfrontação, PD, primeiramente, dialoga com os alunos sobre uma equação que passou na aula anterior, como tarefa de casa; em seguida, convida uma aluna para ir ao quadro e resolver a equação; enquanto a aluna desenvolve a equação em uma parte do quadro, o professor apaga a outra parte do quadro; o professor percebe que a aluna estava com dificuldades em determinada parte da equação e intervém, ao que a aluna responde "ah entendi".

A seguir, apresenta-se um exemplo extraído do trecho de autoconfrontação em que o professor estava relatando uma dúvida sobre a utilidade de perguntas que ele faz em sala de aula, tal como "entenderam?", e de respostas dos alunos, tal como "entendi" que ocorrem nas explicações.

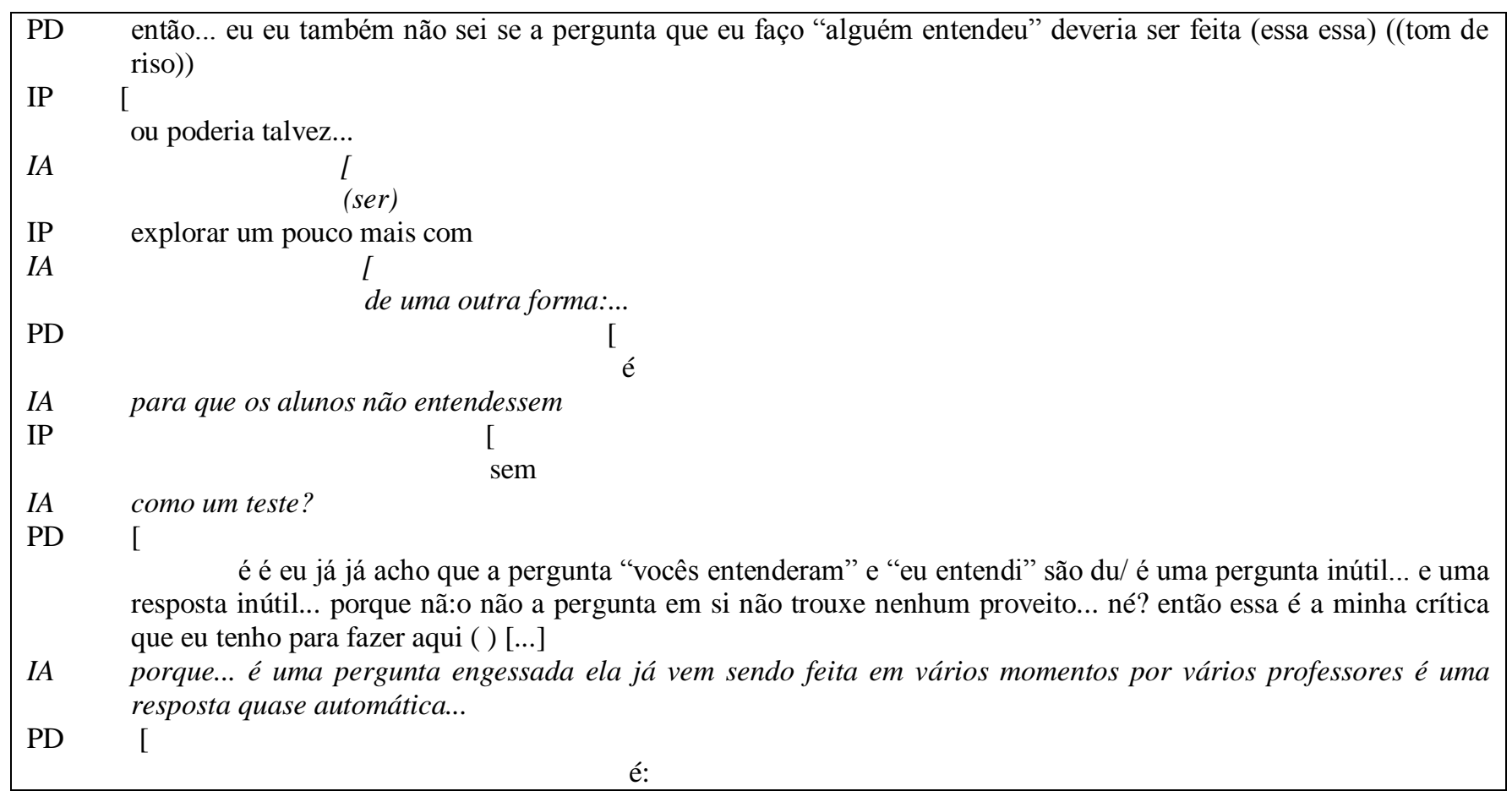


Diante da explanação do PD sobre sua dúvida em relação à utilidade de perguntas e respostas, tais como "entenderam?" e "entendemos", IP tenta colocar uma questão procurando investigar se isso poderia ser feito de outra forma. A pergunta de IP seria: "ou poderia talvez... explorar um pouco mais com". Mas, IP é interrompida após o "talvez" por IA que, timidamente, introduz de uma forma quase incompreensível: "(ser)". IP dá continuidade ao seu enunciado: "explorar um pouco mais com". Novamente IA interrompe IP e complementa a fala desta: "de uma outra forma:... para que os alunos não entendessem como um teste?". Depois que IA diz "de outra forma", PD concorda: " $e$ ", e, IP busca, por sua vez, retomar a palavra com "sem". Desse modo, IA conclui a pergunta que IP havia iniciado quando foi interrompida por IA. A questão toda é: IP, "ou poderia talvez... explorar um pouco mais"; IA, "de uma outra forma:... para que os alunos não entendessem como um teste?". É como se IA colasse sua fala na IP para intervir de forma mais segura, de tal modo que a palavra de IP se torna palavra de IA. Inicialmente, IA se lança timidamente, pois embora sobrepondo-se à voz de IP, a sua fala é quase incompreensível; recua e volta a se sobrepor à IP para lhe complementar; e, passa para a finalização da pergunta ao PD. Trata-se de um processo de transformação que inicia lentamente e vai tomando forma, passando do papel de auxiliar para o de interveniente principal. A resposta de PD não é de concordância de que a pergunta "entenderam" seria um teste, mas de que é "inútil", que não traz "nenhum proveito". Diante disso, IA diz com outras palavras o que PD tentava manifestar: "porque... é uma pergunta engessada ela já vem sendo feita em vários momentos por vários professores é uma resposta quase automática". Com o que o PD concorda. Percebe-se que IA faz um esforço em ser interveniente de duas formas: uma complementando a fala de IP e outra ajudando o PD a organizar seu discurso.

Considerando esses três momentos da interveniente em formação pode-se perceber três modos diferentes da Interveniente Auxiliar se lançar em sua tarefa. No primeiro momento, IA inicia timidamente, vai aos poucos se colocando no diálogo e faz uma pergunta que leva o PB a explicitar melhor o que ele vinha tentando explicar sobre correções de exercício. No segundo momento, IA é mais contundente, inicia a pergunta de forma mais firme e, de fato, lança uma provocação ao se referir à "estratégia" a ser empregada, modificada, transformada, ao longo das aulas; essa provocação parece ter tido um efeito em PC, que nega ter "estratégias", a não ser de maneira a desviar o foco de seu trabalho. No terceiro momento, IA se articula com IP para questionar o professor e se posiciona de forma atenta ao que o PD tenta explicar, ajudando-o a organizar seu discurso, empregando outras palavras.

\section{Considerações finais}

O interesse em melhor compreender o papel do interveniente em CA e sua constituição levounos a examinar algumas afirmações a respeito dessa figura central. Uma discussão recente sobre intervenção e pesquisa, e a possibilidade ou não de realizá-las, simultaneamente (BANKS-LEITE; SMOLKA; ANJOS, 2016), deixou alguns pontos em aberto, pois mesmo os que defendem que a pesquisa deve se iniciar quando a intervenção acaba, usam indistintamente o termo pesquisador para se referir ao interveniente ou mesmo pesquisador-clínico.

Com o intuito de melhor conhecer esse terreno, foram trazidos alguns elementos para esclarecer o que é a Clínica e o campo do trabalho clínico. $\mathrm{Na}$ área da psicologia, o termo pode ser tanto um adjetivo, como também um substantivo, sendo empregado na pesquisa e na prática. Como adjetivo foi usado desde finais do século XIX, em psicopatologia, para estudar casos de sujeitos face a suas dificuldades e logo passou a ser empregado em outras áreas. $\mathrm{O}$ aspecto casuístico, entretanto, permaneceu como uma marca específica do método e/ ou da démarche clínica, contrapondo-se, portanto, a outros modos de atuação. Lembre-se que os testes ou métodos psicométricos, caracterizados por situações padronizadas, dominaram, principalmente, durante a primeira metade do século XX e são ainda bastante empregados tanto na psicologia como em áreas da medicina e afins. Por se afastar desse tipo de quadro fixo, tal démarche exige a intervenção de alguém que domine um campo de conhecimentos teóricos e um saber-fazer específico.

Assim sendo, na Clínica da Atividade, a atuação do psicólogo/ clínico/ interveniente/ pesquisador exige, além do domínio de certos conceitos e de um corpo de conhecimentos dessa área, que se tenha experiência. E é nesse sentido que uma discussão sobre a formação surge como importante e necessária, questão essa tratada na 
O interveniente em clínica da atividade: considerações sobre seu papel e sua formação

terceira parte do texto.

No caso em estudo, a formação de interveniente é realizada no âmbito de um grupo de pesquisa e envolve momentos de estudos de conceitos da CA e momentos de experiência em autoconfrontação com o acompanhamento de uma interveniente mais experiente. Com inspiração nas afirmações Vigotsky, acredita-se que alguém menos capaz/ menos experiente pode aprender com outro mais experiente de forma a se desenvolver nessa prática.

Os dados empíricos apontam modos de fazer no movimento dialógico de uma interveniente em formação, durante suas primeiras participações em autoconfrontações simples. Assim sendo, constatou-se que, em um primeiro momento, ela inicia de forma mais tímida, mas adquire mais confiança em sua participação. Em um outro momento, participa com mais firmeza e "ousa" provocar, o que leva a claros efeitos do professor em confrontação. Em um terceiro momento, ela intervém para complementar a interveniente principal e o professor.

No conjunto, nota-se que ela está em processo de "tateamento", mas age de forma espontânea, o que às vezes parece ter certa eficácia como se nota no segundo momento.

Em todo caso, o estudo em andamento indica a necessidade de se levar a sério a formação do interveniente, no exercício de suas funções, de maneira a que ele seja acompanhado e mesmo supervisionado em suas atuações iniciais.

\section{Notas}

1 Apesar das críticas de seus contemporâneos ao "egocentrismo infantil", tal como descrito nesses primeiros trabalhos, esse método foi bastante elogiado por pesquisadores como Wallon, Blondel, Claparède e Vigotski (BANKS-LEITE, 2011).

2 Inspirando-se nos trabalhos de Bakhtin a respeito de Gêneros de Discurso, Clot elabora o conceito de Gênero de Atividade, relacionado ao exercício profissional (Bakhtin, 1979/2011; CLOT, 1999/2006).

3 Saint-Exupéry aponta, em seus livros, como as experiências dos mais velhos constitui um elemento essencial para a aprendizagem do métier de piloto (cf. primeiro capítulo de Terres des Hommes).

4 Trata-se de uma pesquisa de doutoramento, em andamento, cujo objetivo principal é o estudo da formação do interveniente, tal como se realiza nessa instituição. Neste texto, são apresentados apenas alguns dados referentes a essa investigação.

5 As normas adotadas para transcrição são as seguintes: "( )", palavras não compreendidas; "(x)", hipótese do que se ouve; "/", truncamentos na fala; "XXX", entonação na fala; ":", prolongamento; “-”, silabação; “...”, pausa; "((x))", comentários do transcritor; "-- x --", digressão na sequência temática; "[", sobreposição de vozes; "”, citações literais (PRETI, 2001). A marcação “[...]" indica que parte da transcrição foi cortada.

\section{Referências}

ALTHAUS, D. Complexidade e Relevância de um Gesto Profissional Docente Aparentemente Simples. 2013. 200 f. Dissertação (Mestrado em Desenvolvimento Regional) - Programa de PósGraduação em Desenvolvimento Regional, Universidade Tecnológica Federal do Paraná. Pato Branco, 2013.

BAKHTIN, M. (Voloshinov). Estética da criação verbal. Trad. Paulo Bezerra. 4. ed. São Paulo: Martins Fontes, 1979/2011.

BANKS-LEITE, L. Os primeiros trabalhos de Piaget: a interlocução com seus contemporâneos. Linguagem, conhecimento e desenvolvimento humano: três estudos. Tese de Livre Docência, FE/Unicamp-2011.

BANKS-LEITE, L.; SMOLKA, A. L.; ANJOS, Daniela D. (org.) Diálogos na perspectiva históricocultural: interlocuções com a clínica da atividade. Campinas: Mercado das Letras, 2016.

BRASIL. Lei 9394 - LDBEN - Lei das Diretrizes e Bases da Educação Nacional. 1996.

CLOT, Y. A função psicológica do trabalho. Trad. Adail Sobral. Petrópolis, RJ, Editora Vozes, 1999/2006.

La recherche fondamentale de terrain : une troisième voie. Education Permanente, vol 4, 
n. 177,2008

Trabalho e poder de agir. Trad. Guilherme João de Freitas Teixeira e Marlene Machado Zica Vianna. Belo Horizonte: Fabrefactum, 2008/2010.

CLOT, Y.; LEPLAT, J. La méthode clinique em ergonomie et em psychologie du travail. In: Le travail humain. Paris: Presses Universitaires de France, vol. 68, n. 4, 2005, p. 289-316.

LEITE, J. C. C. (org.). UTFPR: uma história de 100 anos. Curitiba: Ed. UTFPR, 2010.

LEITE, S. A. S.; BERNARDO, F. O.; MOREIRA, A. L. A. Espaço de formação pedagógica para o docente no ensino superior: entrevista com Sérgio Leite. REVISTA DOCENCIA DO ENSINO SUPERIOR, v. 7, p. 211-221, 2017.

OSORIO DA SILVA, C. Pesquisa e intervenção: movimentos que se cruzam e coexistem, em mutua interferência. In: BANKS-LEITE, L.; SMOLKA, A. L. e ANJOS, D. D. (org.) Diálogos na perspectiva histórico-cultural: interlocuções com a clínica da atividade. Campinas: Mercado das Letras, 2016, p.153-168.

PIAGET, J. (1966). Autobiographie, Cahiers Vilfredo Pareto, 10, pp. 129- 159.

PIMENTA, S. G.; ANASTASIOU, Lea. G. C. Docência no ensino superior. 4. ed. São Paulo: Cortez, 2002/2010.

REUCHLIN, M. Os métodos em Psicologia. Rio de Janeiro: DIFEL, 1969/1971

VIGOTSKI, L. S. Formação social da mente. Org. Michel Cole [et al]. Trad. José Cipolla Neto, Luís Silveira Barreto e Solange Castro Afeche. 7.ed. São Paulo: Martins Fontes, 1984/2007.

\section{Sobre os autores:}

Dalvane Althaus é bolsista da Fundação Araucária. Pedagoga na UTFPR-PB. Doutoranda em Educação pela Unicamp. Membro do Grupo de Pesquisa Linguagem, Atividade e Desenvolvimento Humano (LAD'Humano) e do Grupo de Pesquisa Pensamento e Linguagem (GPPL).

Luci Banks é pesquisadora Colaboradora da Faculdade de Educação da Unicamp. Membro do Grupo de Pesquisa Pensamento e Linguagem (GPPL).

Recebido em setembro de 2017.

Aprovado em outubro de 2017. 